\title{
SIGNIFICADO DA BIODANÇA COMO FONTE DE LIBERDADE E AUTONOMIA NA AUTO-RECONQUISTA NO VIVER HUMANO ${ }^{1}$ THE MEANING OF THE BIODANCE AS A SOURCE OF FREEDOM AND AUTONOMY IN RECONQUERING ONESELF IN HUMAN LIVING \\ EL SENTIDO DE LA BIODANZA COMO FUENTE DE LIBERTAD Y AUTONOMÍA EN LA RECONQUISTA DE SÍ MISMO EN EL VIVIR HUMANO
}

\author{
Bárbara Pereira d'Alencar ${ }^{2}$, Maria Manuela Rino Mendes ${ }^{3}$, Maria Salete Bessa Jorge $e^{4}$, Maria do Socorro Pereira Rodrigues ${ }^{5}$
}

${ }^{1}$ Este estudo faz parte de uma pesquisa maior representada pela tese de doutorado da primeira autora, denominada: "Biodança como processo de renovação existencial do idoso: análise etnográfica”, defendida em 2005, na Universidade de São Paulo (USP).

2 Enfermeira. Doutora em Enfermagem. Professora do Colegiado de Enfermagem da Universidade Estadual do Ceará (UECE). Ceará, Brasil.

${ }^{3}$ Enfermeira. Doutora em Enfermagem. Professora do Programa Interunidades de Doutoramento em Enfermagem da Escola de Enfermagem de Ribeirão Preto da USP. Orientadora do estudo. São Paulo, Brasil.

${ }^{4}$ Enfermeira. Doutora em Enfermagem. Professora do Colegiado de Medicina e Coordenadora do Mestrado de Saúde Pública da UECE. Ceará, Brasil.

${ }^{5}$ Enfermeira. Doutora em Enfermagem. Professora do Curso de Enfermagem da Universidade Federal do Ceará (UFC). Ceará, Brasil.

PALAVRAS-CHAVE: Idoso. Promoção da saúde. Terapia através da dança.

KEYWORDS: Aged. Health promotion. Dance therapy.

PALABRAS CLAVE: Anciano. Promoción de la salud. Terapia a traves de la danza.
RESUMO: O objetivo foi compreender o significado da biodança para idosos do Grupo de Biodança do Serviço Social do Comércio de Fortaleza, Ceará, Brasil. Como método de investigação optou-se por etnografia. A biodança tem como referencial imediato a vida, e é definida como um sistema de integração e desenvolvimento humano, orientado para o estudo e a expressão das potencialidades humanas induzidas pela música, pela dança, por exercícios de comunicação em grupo e vivências integradoras. Adotaram-se entrevistas analisadas pelo método de análise de narrativa. Conforme revelou o processo de análise e interpretação, a biodança melhora as condições de saúde dos idosos, por aumentar a vontade de viver; ajuda-os a se sentirem inseridos no mundo e propicia a vivência com autonomia, ao estimular a busca de projetos existenciais. Assim, a biodança promove a renovação existencial dos idosos e poderá ser uma estratégia utilizada pelos enfermeiros no processo do cuidado humano.

ABSTRACT: The objective of this study was to comprehend the meaning of the biodance to elderly in a Biodance Group from Social Services of Commerce from Fortaleza, Ceará, Brazil. The method of investigation was ethnography. The immediate reference of the biodance is life itself and is defined as a system of human integration and development, oriented to the study and expression of human potentialities induced by music, dance, group communication exercises, and integrated living experiences. The interviews were analyzed by the narrative analysis method. The process of analysis and interpretation revealed that the biodance betters the health conditions of the elderly, due to increasing their will to live; helping them to feel themselves inserted in the world and promoting autonomous living, as well as stimulating the search for existential projects. Thus, the dance promotes the existential renewal of the elderly and may be a strategy used by nurses in the process of human care.

RESUMEN: El objetivo de este estudio fue comprender el sentido de la biodanza para los ancianos del Grupo de Biodanza del Servicio Social del Comercio de Fortaleza-Ceará, Brasil. El método de investigación fue etnográfico. La biodanza tiene como referencial inmediato la vida y es definida como un sistema de integración y desarrollo humano, orientado para el estudio y la expresión de las potencialidades humanas inducidas por la música, la danza, por ejercicios de comunicación grupal y vivencias integradoras. Para el estudio se utilizaron entrevistas, las cuales fueron analizadas por el método de análisis de la narración. El proceso de análisis e interpretación ha revelado que la biodanza mejora las condiciones de salud de los ancianos al aumentar su deseo de vivir, los ayuda a sentirse inseridos en el mundo y propicia la vivencia con autonomía, al estimular la búsqueda de proyectos existenciales. De esa forma, la biodanza promueve la renovación existencial de los ancianos y podrá ser una estrategia utilizada por los enfermeros en el proceso del cuidado humano.
Endereço: Bárbara Pereira d' Alencar

R. São Mateus, 1515, casa 4, Condomínio São Mateus

60.410-640 - Vila União, Fortaleza, CE, Brasil.

E-mail: barbara-alencar@ig.com.br
Artigo original: Pesquisa

Recebido em: 01/11/2006

Aprovação final: 31/05/2007 


\section{INTRODUÇÃO}

Os sentimentos podem levar à percepção e despertar a compreensão quanto ao viver, estar e pertencer ao mundo, a partir dos efeitos emocionais e psicológicos do existir, do interagir em sua forma integral. Para bem viver, cada pessoa deve encontrar seu ponto de equilíbrio com base nas reações e nas condições disponibilizadas ou buscadas por ela. Este ponto de equilíbrio pode ser encontrado também pela forma de cada indivíduo orientar suas ações no viver e no atuar no mundo. Nesse processo, todos são influenciados pela cultura - valores, crenças, hábitos, costumes e idéias, fundamentadas em regras que caracterizam e sustentam a sociedade, nas várias dimensões da vida humana. ${ }^{1-2}$ Dessas dimensões, faz parte a liberdade, entendida como princípio que modela as instituições da vida coletiva, integra um núcleo de princípios de cidadania, baseada nos valores da escolha individual, cujo exercício se apóia no pressuposto de que os cidadãos e cidadãs sejam pessoas emancipadas, capacitadas a escolhas autônomas e à quebra de obstáculos para o alcance do crescimento necessário ou desejado. É, invariavelmente, um sentimento permeado de satisfação, intimamente associada à autonomia do ser pensante e influente na promoção do processo dinâmico de desenvolvimento, tendo em conta também o ponto de vista de outros. Envolve sentimentos e emoções, desejos, sonhos e está fundada na ética, no respeito à dignidade. Uma pessoa autônoma é capaz de deliberar sobre seus objetivos pessoais e de agir na direção desta deliberação, sempre respeitando a autonomia. Respeitar a autonomia é valorizar a consideração sobre as opiniões e escolhas; ser soberano sobre si mesmo, sobre seu corpo e sua mente. Agir livremente de acordo com um plano próprio, administrar seu território e estabelecer suas políticas. Pela interação com o outro no contexto dos fatos e dos atos, pode-se tomar consciência das próprias defesas, condescendências e generosidade. Isto dá a verdadeira dimensão de ser, estar e pertencer ao mundo, reforçando a vitalidade em uma identidade saudável, de forma a encontrar o verdadeiro significado da existência. ${ }^{3}$

Contudo, os modos de subjetivação, expressão de sentimentos, as formas de interação do sujeito no contexto dos atos e fatos são dinâmicos. Portanto, podem ser influenciados por diversos fatores, entre eles, a fase do ciclo de vida.

$\mathrm{Na}$ velhice, por exemplo, ocorrem diversas transformações na vida do indivíduo, não somente no aspecto biológico, mas também no psicossocial.
Nesse ciclo biológico, quase sempre as pessoas, têm seu tempo disponível/livre ampliado em virtude da aposentadoria, crescimento e independência dos filhos. Tais situações, em geral, desencadeiam sentimentos de inutilidade, de solidão e, muitas vezes, de dependência. Diante disto, constituem motivos de intenso sofrimento.

Neste contexto, a Biodança tem-se demonstrado capaz de melhorar a qualidade de vida interior do idoso de qualquer camada social, ao lhe possibilitar sentir-se bem. Conseqüentemente, promove a harmonização com o mundo ao seu redor. ${ }^{4}$

A partir destas considerações algumas questões nortearam a realização deste estudo. Entre elas mencionam-se as seguintes: como a pessoa foi sensibilizada para a Biodança? $O$ que significa a Biodança para os idosos que a vivenciam? Como a Biodança tem influenciado a saúde e qualidade de vida dos idosos que a vivenciam?

Deste modo, elegeu-se como objetivo da pesquisa compreender o significado da Biodança para idosos que a vivenciam no Grupo de Biodança do Serviço Social do Comércio (SESC) de Fortaleza - Ceará.

\section{PERCURSO METODOLÓGICO}

Esta é uma pesquisa descritiva e qualitativa, centrada no enfoque hermenêutico, ${ }^{5}$ a fim de obter, a partir do conteúdo de narrativas de um grupo de idosos, o significado de vida com qualidade. A população constou de oito pessoas, um homem e sete mulheres, de um grupo de quinze idosos que se reúnem na sede do SESC, na cidade de Fortaleza, para praticar a Biodança, entendida como um sistema de integração e desenvolvimento humano orientado para o estudo e a expressão das potencialidades humanas, por meio da dança, exercícios de comunicação e vivências integradoras induzidas pela música. ${ }^{6} \mathrm{Os}$ critérios de inclusão foram pertencer ao Grupo de Biodança do SESC/CE, praticá-la há mais de um ano e desejar voluntariamente responder a uma entrevista semi-estruturada, cuja pergunta norteadora foi a seguinte: $\mathrm{O}$ que significa a Biodança para você?

Para captação das narrativas utilizou-se como técnica a entrevista semi-estruturada, focalizada na problemática a ser estudada com base na questão norteadora e orientada por um roteiro que permitia, sempre que necessário, a retomada do tema central. As informações também foram obtidas por meio de observação participante no grupo, durante vinte meses, quando eram feitos registros em diário de campo. 
As observações participantes têm o objetivo de compreender e experienciar a dinâmica dos atos e eventos, assim como recolher informações a partir da compreensão e sentido que os atores atribuem aos seus atos. ${ }^{7}$ Essa modalidade de imersão no grupo facilita a percepção de atos ou eventos dificilmente captáveis pela entrevista ou observação. Assim, permite um relacionamento mais direto com seus atores sociais, ou seja, fazendo parte do grupo, podendo tanto modificar o contexto como ser modificada por ele. O registro das falas no diário de campo, logo após as sessões de Biodança, propiciou a captação das falas, das emoções manifestadas pelos atores, bem como sua participação no grupo e o registro detalhado da leitura corporal dos idosos. Tais observações foram organizadas numa agenda específica para orientar as anotações, as quais complementam a análise dos dados colhidos nas entrevistas semi-estruturadas.

Por se constituir numa pesquisa no âmbito do processo grupal envolvendo as falas, opiniões e ações das pessoas integrantes de um grupo, buscou-se dar atenção especial aos aspectos éticos envolvidos na pesquisa. Neste sentido, o trabalho foi submetido à aprovação pelo Comitê de Ética em Pesquisa da Universidade Estadual do Ceará, e obteve parecer favorável (Protocolo s/n, 31/3/2005). Para manutenção do anonimato, conforme exigido, os entrevistados foram identificados por nomes de flores, tais como Girassol, Papoula, Margarida, Saudade, Jasmim, Flor de Lótus, Acácia e Rosa Amélia, nomes escolhidos por eles próprios.

Todo o material colhido nas entrevistas foi analisado e interpretado à luz da linguagem mais geral, confrontado com as outras informações da pesquisa registradas no diário de campo e com as narrativas dos entrevistados, partindo do pressuposto de que "a interpretação se coloca entre a linguagem e a vida vivenciada, por meio de uma série de conceitos interpretativos entre os quais o distanciamento, a apropriação, a explicação e a compreensão" 8:133

Considerando a coerência entre a abordagem hermenêutica e a interpretação das culturas e para a elucidação do significado, o desvelamento do sentido, sedimentando uma compreensão acerca do mundo, optou-se por analisar os dados das narrativas dos idosos participantes do Grupo de Biodança. Assim, a interpretação direcionou-se para a análise das relações internas do texto, que representa as partes do discurso e tenta compreender os significados revelados por estes, ou seja, o todo em relação às partes. Neste sentido, interpretar o texto consiste em desvelar qual a mensagem implícita no discurso, que é um acontecimento a ocorrer no tempo, quando alguém se expressa ao falar, na tentativa de descrever ou representar seu mundo. ${ }^{9}$

Os passos metodológicos, seguidos para objetivação do texto, possibilitam o distanciamento e a apropriação, e juntamente com a explicação e a compreensão vão permear a interpretação: a efetuação da linguagem como discurso; a efetuação do discurso como obra estruturada; a relação da fala com a escrita no discurso e nas obras do discurso; a obra do discurso como projeção de um mundo; o discurso e a obra de discurso como mediadores da compreensão de si. ${ }^{5}$

Para desenvolver o método de análise de narrativa buscou-se revelar o significado da experiência vivida pelos sujeitos, pela interpretação de suas narrativas transcritas no texto obtido com as entrevistas. ${ }^{5}$ Assim, de acordo com este método, interpretar é um processo que envolve os seguintes passos metodológicos:

- fixação das entrevistas num texto - captouse a história vivenciada pelos idosos, por meio de entrevistas expressadas na linguagem; em seguida fez-se a transcrição do discurso num texto, para depois ser interpretado;

- leitura simples do material - esta leitura permitiu uma compreensão do significado do texto em sua totalidade;

- análise estrutural das narrativas - conduzida em direção à estrutura de cada texto, propiciou examiná-lo inteiramente em termos de entidades distintas, as unidades de significado (segmentos do discurso explicitativo no texto, que formam uma unidade de sentido) com a finalidade de explicar aquilo que o discurso está dizendo, seguida da busca de citação dos autores que respaldam teoricamente os achados;

- compreensão abrangente ou profunda - este passo leva à compreensão do que o texto fala. Esse entendimento das narrativas nos dá a certeza de que as histórias contadas revelam a importância atribuída àquela situação ou à experiência, o significado daquele evento na vida da pessoa. ${ }^{10}$

Neste estudo, a teoria interpretativa eleita para análise dos dados oportuniza a compreensão do expresso e do não expresso no discurso. A interpretação simples e profunda favorece o entendimento das partes do texto em relação ao todo e vice-versa e, desse modo, facilita uma reflexão sobre os diferentes temas que emergem das entrevistas de 
idosos praticantes da Biodança. Com esta finalidade, buscou-se entender os sentidos do texto que levaram à compreensão da vivência de Biodança no viver desses idosos, suas descobertas e ressignificados.

\section{A DESCOBERTA DA BIODANÇA}

A Biodança eu encontrei por acaso, recebi um convite de uma pessoa amiga, minha vida estava muito péssima... Tava mais ou menos $80 \%$ péssima de ruim, porque eu estava passando por uma fase de separação, de briga... Eu agradeço muitas às pessoas amigas, pois quase corria sangue no meio... Mas evitei porque a pessoa tem que parar para pensar, para fazer as coisas... Tem que pensar primeiro em Deus... Ai a Biodança surgiu para mim (Girassol).

Girassol fala sobre como encontrou a Biodança. Contudo, são diversas as formas da pessoa chegar a um grupo de Biodança; quase sempre prevalece a indicação de alguém. Muitas vezes, nas sessões iniciais, há até um número razoável de pessoas, mas algumas se afastam. Provavelmente isso se explica pelo fato da Biodança mobilizar estruturas pessoais rígidas sedimentadas desde a infância, denominadas em estudo de mandatos antivida, expressos por: não toquem, não vivam, não se mexam, não tenham prazer, entre outros. ${ }^{3}$ Ao longo da vida, vamos escutando esses mandatos, os quais vão formando uma couraça de caráter, composta por distúrbios da identidade, que se tenta a todo custo manter. ${ }^{11}$

Aqui, Flor de Lótus narra como chegou à Biodança, com tantas repressões em relação ao contato físico e expressão dos sentimentos, que lentamente foi superando.

Levada por uma amiga, eu conheci a Biodança e lá se vão 11 anos. E foi muito bom o relacionamento que en tive com outras pessoas, porque exatamente... A gente não cresce só... Sempre acompanbada... Biodança é assim uma coisa maravilhosa e na terceira idade então... É uma coisa assim, muito gostosa, porque a maioria das pessoas começa às vezes a ficar deprimida, porque vai ficar com muita idade... Pensa que já tá perto de morrer e não é assim. A gente tem é que viver... Viver o dia de hoje. O dia de hoje é o presente... É um verdadeiro presente, o dia de hoje... O dia de ontem já é passado. A gente não pode remendar e o amanhã você nem sabe como vai ser... Então a gente tem que viver muito bem o dia de hoje, aproveitar o momento presente (Flor de Lótus).

As mudanças em Jasmim foram muito sutis, pois sua resistência era grande. Agora está buscando ampliar sua rede de relacionamentos e decidir o que quer fazer com a revelação de sua timidez. Via no grupo uma oportunidade para dançar.
Eu não conbecia a Biodança e quando eu entrei no SESC, é que en ouvi falar de Biodança e entrei mais por curiosidade... Eu não sabia o que era... Ai fiquei gostando, foi a oportunidade que en tive para dançar... Gosto de ir ali pra dancar... Porque é uma maneira de dançar, porque eu não tenho coragem. Em festa não tenho coragem. Eu queria ter essa vontade de dançar, mas a timidez não deixa... Ali eu me solto. Gosto de ir ali pra dançar... Porque é uma maneira de dançar, porque eu não tenho coragem. Em festa não tenho coragem. Eu queria ter essa vontade de dançar, mas a timidez não deixa... Ali eu me solto (Jasmim).

\section{AUTOPERCEPÇÃO DE MUDANÇAS A PARTIR DA BIODANÇA}

Acácia fala do receio que tinha de mudar com a Biodança. Agora, porém, vem se reconhecendo modificada no enfrentamento do dia-a-dia.

Um pecado meu com a Biodanç. Sério! Sabe por que en não vim logo?... Eu tinha vontade... Eu tinha medo. Eu fiquei na minha cabeça, que eu ia me soltar muito, sabe? E o negócio é que eu tava me fechando, me segurando, me fechando como uma ostra. Só que eu vi que não era a minha vida (Acácia).

Como se pode observar, a Biodança tem incentivado as pessoas a melhorarem a qualidade de suas vidas, a exemplo do ocorrido com Margarida, que já participava de outra atividade no SESC, quando teve a chance de conhecer a Biodança.

Depois da Biodança eu me modifiquei muito... muito... muito. Eu tô me sentindo bem. Tô mais disposta, mais ativa. Tô mais ativa do que en era. Falava muito menos... Falava mais baixinho. Eu era muito tímida... Agora estou muito menos tímida (Margarida).

Outra participante, Rosa Amélia, recomenda a Biodança ao perceber os efeitos benéficos em si mesma.

A Biodança é muito boa não só pra mim, mas pra todo mundo. As pessoas se desinibem e fazem os movimentos, ninguém sabe se tá certo ou errado, se tá feio ou se tá bonito, todo mundo faz (Rosa Amélia).

\section{PROCESSO PERMANENTE DE RENOVA- ÇÃO EXISTENCIAL}

De acordo com o processo de permanente renovação existencial do ser humano, a certos intervalos, as pessoas morrem para tudo que conserva velhas atitudes do passado, abandonando fontes de sofrimento e de conflito, para renascer em um corpo renovado, em uma forma de vida mais salutar e feliz. ${ }^{3}$ 
Também na Biodança há renovação. Nela o sentido de renovação existencial tem o mesmo sentido da autopoiese, pois as transformações ocorrem tanto em nível biológico, quando observamos a melhora na qualidade da saúde; quanto no plano mental, ao percebermos que as pessoas se revelam mais integradas consigo mesmas, mais harmonizadas e felizes, e, no plano social, quando as pessoas buscam melhor integração com os outros e com o ambiente a sua volta. Poiesis é um termo grego que significa produção; autopoiese, portanto, significa autoprodução. Esta palavra foi cunhada por Humberto Maturana e Francisco Varela na década de 1970, para definir o ser humano como sistemas que se produzem continuamente e, para isso, faz-se necessária a interação com o meio ambiente, ambos se modificando de forma congruente. ${ }^{12}$ Assim, nos depoimentos a seguir, evidencia-se o processo de renovação existencial sendo gerado:

A Biodanca eu achei fundamental na minha vida, me mudou totalmente. Primeiro, eu fiquei desinibida. Foi o amor que en passei a sentir pelas pessoas. Eu tinha um defeito de... a gente não se abraçava, não se beijava... e eu passei a abraçar e beijar as pessoas. A gente vai sentindo que as nossas emoções e os nossos problemas são tão parecidos com as outras pessoas e isso é um consolo... criação (Flor de Lótus).

Da Biodança eu gosto de tudo. Principalmente eu gosto da professora e a parte que eu mais gosto é da roda, do colo, daquelas danças, eu acho interessante e gosto muito. Eu sinto aquele carinho, aquele aconchego. Antigamente eu não tinha esse aconchego, nem na minha casa. Era falta de costume abraçar (Saudade).

Eu me modifiquei muito... Me desenvolvi tanto... Tanto fisicamente, que eu não me sustentava, não agüentava sentar no chão... Como mentalmente, porque minha mente tem se modificado muito, muito mesmo. Eu hoje sou outra pessoa (Margarida).

Antes da Biodança, eu acho que toda vida me relacionei bem com as pessoas, nunca tive dificuldades... mas depois da Biodança melhorou mais. Eu conversar, eu me abrir assim? Porque depois da Biodança a gente tem mais facilidade de se expressar... tudo da Biodança eu gosto... eu acho que eu me sinto bem lá... fazer aquelas vivências... Eu fico feliz com aqueles exercícios de acariciamento, de dança... (Rosa Amélia).

A mudança de postura perante a vida também é revelada na narrativa de Acácia, a seguir.

É muito interessante... eu era uma pessoa muito receosa de dar conselho. Eu passei a vida toda, todo mundo me mandando: faça isso, faça aquilo... eles mastigavam pra eu engolir. Eu não gosto de ser mandada. Hoje eu não gosto de dizer as coisas... não gosto de interferir na vida dos outros. Eu peguei e espontaneamente falei... que ela tava querendo ouvir, né? Em tempos atrás eu jamais me colocaria (Acácia).

Saudade também se percebe inovando em seu cotidiano e hoje busca mais novidades para sua vida.

Nunca pensei em fazer hidroginástica, nem sabia o que era. Não dançava não. Essas festinhas do SESC... parece que eu comecei primeiro pela hidroginástica, foi quando a Margarida me convidou e, com aqueles calendários de festas todo mês, os passeios, eu fui me entrosando e hoje eu já sou até uma foliã (Saudade).

Outras vezes as mudanças são identificadas pelas pessoas do círculo de convivência: [... ] criatividade... como eu sempre tive facilidade, isso para mim é maravilhoso, porque eu diria, é ser. Eu vim descobrir que era criativa exatamente na Biodança. Alguém disse e eu não sabia (Papoula).

\section{LIBERDADE}

$\mathrm{Na}$ reconstrução do cotidiano dos participantes desta pesquisa, tendo em vista as narrativas acerca dos significados da Biodança em suas vidas, emergiu a liberdade, percebida como "soltar as amarras" a que o idoso é condicionado pelos controles sociais.

A libertação de certos controles sociais relativos à vida familiar vem entusiasmando mulheres idosas numa referência aos costumes restritivos, ao cerceamento da família e sociedade, como foi expresso por Papoula, que durante toda a vida foi superprotegida e vigiada pelos pais, embora lhe desagradasse muito. Os discursos desvelam a experiência.

Dizem que a vida começa aos 40. Eu diria que a minha começou aos 44 anos, no meu primeiro ano de Biodança, e cada dia vem recomeçando. Este ano estou participando de um bloco pré-carnaval, que desfila na Praia de Iracema. Dizer como estou me sentindo é difícil. Só vendo pra crer e fotos mostraram isso. É de causar espanto a quem me conbece (Papoula).

Participar do bloco de carnaval também foi uma libertação para Saudade, que passou toda sua vida cuidando de pessoas, e jamais teve oportunidade de lazer. Agora consegue entrar num bloco carnavalesco junto com os amigos da Biodança e assim traduz sua experiência.

Agora melhorou 100\%. Arranjei muitas amizades. Já tô até no bloco "Comigo ninguém pode", o carnaval que sai da Praia de Iracema. Fico de quatro às oito, é uma maravilha. Fico arrodeada de amigos. Minha vida vai maravilhosamente bem. O bloco de carnaval... Os meus filhos tudo são de acordo. E ai eu digo: minha filha, agora é que eu tô vivendo, porque quando eu era mais nova eu não vivi minha vida. Sempre cuidei dos irmãos, depois cuidei do marido, depois cuidei de minha tia e teve o men pai também. O carnaval... por quê é que en 
tenho esse fogo pelo carnaval?... porque en nunca brinquei carnaval. No interior, eu era de dentro da igreja, presidente das associações, e era proibido até olhar as festas, né... Dança... de jeito nenhum. Acho que é por isso que eu tenho essa vontade de brincar, acho que é por isso. Nunca pensei em fazer o que eu tô fazendo hoje (Saudade).

De modo geral, a conquista da liberdade é vista como um apanágio de uma velhice bem sucedida, geradora de satisfação. A satisfação com a vida como medida de bem-estar envolve determinados aspectos, como os seguintes: entusiasmo, determinação e fortaleza, congruência entre os objetivos desejados e os alcançados, o conceito positivo de si mesmo e o bom humor. ${ }^{13} \mathrm{E}$ é tudo isso que se pode perceber na última narrativa, pois para Saudade as atividades realizadas em grupos de amigos possibilitam a alegria de viver, o estreitamento do convívio social e o restabelecimento da comunicação, das relações solidárias, a cooperação e apoio mútuo. Tudo isso torna mais agradável a vida da pessoa idosa.

\section{CONSIDERAÇÕES FINAIS}

Como mostra a realidade, existe um movimento recíproco do indivíduo e da sociedade, destinado a manter o idoso afastado do meio social. E, à medida que ele se distancia, a sociedade oferece-lhe menos possibilidades de se integrar com outros. Ao mesmo tempo, a limitação do idoso ao ambiente do lar reduz seus contatos sociais e gera introspecção. Desse modo, a pessoa é impossibilitada de desfrutar da sua liberdade.

A Biodança, porém, rompe com esse movimento, ao promover a integração com outras pessoas. Ao estimular o idoso a participar de eventos em grupos, esta atividade aumenta o sentimento de pertença ao mundo e estimula a alegria de viver, pois proporciona a renovação da sociabilidade e reforça os vínculos familiares e entre amigos. Neste sentido, por ser a Biodança uma atividade grupal, o processo de crescimento é permeado pela interação com os outros, e esta leva à evolução, pois não existe evolução solitária. Interagir é um ato criativo, um impulso para constante transformação.

No estudo pôde-se testemunhar o processo de metamorfose: idosos saíram da restrição de seus casulos, representados pela estrutura de repressão social a que foram submetidos em toda sua existência; foram desabrochando e libertando-se como as borboletas, livres da vergonha e dos preconceitos; descobrindo a possibilidade da expressão de si mesmos, já que a vida se manifesta num contínuo processo de desenvolvimento. Neste sentido, é possível, por meio da Biodança, romper barreiras do medo e do preconceito, graças às forças curativas do amor e da solidariedade.

Todas essas conquistas são visíveis. Quanto aos progressos físicos num grupo de idosos, embora possam parecer lentos e pouco perceptíveis, é uma vitória mobilizar estas pessoas a sair de casa e descobrir o quanto é bom estar com os outros e aconchegar-se no ninho ecológico, sentindo-se parte da espécie humana, podendo se expressar; experimentando tocar e ser tocados, mesmo que um toque apenas, com as pontinhas dos dedos, como faziam Girassol e tantos outros, no início. Afinal, o corpo do outro sempre lhes pareceu um campo minado... E agora podem usar sua pele, não mais como um órgão de defesa ou de separação do outro, mas como elemento de união entre as pessoas. Podem abrir os olhos e descobrir no olhar do outro que é possível o encontro humano. Podem reiniciar a caminhada pela vida, independentemente da idade; no início, com passos vacilantes, mas descobrindo que, com determinação, podem buscar seu projeto existencial. $\mathrm{E}$ assim como o maestro rege a orquestra, é possível reger a própria vida, libertar-se da superproteção e cuidados com que são tratados, e tocar sua própria sinfonia, transformando sua vida numa melodia harmônica!

A partir das narrativas, pôde-se confirmar os pressupostos de que a Biodança pode ajudar no enfrentamento de barreiras impostas aos idosos, expressas pelo preconceito, pelo isolamento social, pela falta de respeito aos seus direitos, quase sempre camuflados pela superproteção ou abandono à solidão, que se inicia dentro de casa. Assim, o idoso, ao perceber sua falta de autonomia, vai buscar sua liberdade, tendo a percepção de que precisa se soltar mais, sair do jugo da família e aproveitar as oportunidades de lazer, de companheirismo, se expressar, caminhar com as próprias pernas e concretizar seus projetos existenciais.

Para os participantes desta pesquisa, a Biodança tem um ponto alto, qual seja, a abertura de perspectivas para uma vida melhor, com mais qualidade e novidades para o cotidiano. Isso só é possível pelo desenvolvimento do potencial criativo, que impulsiona as pessoas a recriarem sua existência.

Ao despertar a mudança interior, também percebida aos olhos dos outros, a Biodança aponta caminhos que promovem a ressocialização dos idosos, pois favorece o lazer, a paz, a tranqüilidade, o 
autoconhecimento, a liberdade, a leveza e a tessitura de vínculos duradouros. Neste sentido, conforme constatou-se, a Biodança promove a renovação existencial dos idosos.

Diante desta e de outras experiências, propõese convalidar a Biodança como uma estratégia passível de ser utilizada pelos enfermeiros no processo do cuidado humano, com vistas à promoção da saúde dos idosos e à prevenção de doenças.

\section{REFERÊNCIAS}

1 Helman CG. Cultura, saúde e doença. 2a. ed. Porto Alegre (RS): Artes Médicas; 1994.

2 Penna, CMM. Realidade e imaginário no processo de viver de moradores em um distrito brasileiro. Texto Contexto Enferm. 2007 Jan-Mar; 16 (1): 80-8.

3 Toro R. Biodanza. São Paulo (SP): Escola Paulista de Biodanza; 2002.

4 D'Alencar BP. O idoso e o trabalho corporal: perspectiva de atuação do enfermeiro [dissertação]. Salvador (BA): UFBA/Programa de Pós-Graduação em Enfermagem; 1988.
5 Ricoeur P. Interpretação e ideologias. Rio de Janeiro (RJ): Francisco Alves; 1990.

6 Toro R. Teoria da biodança. Tomos I e II. Fortaleza (CE): ALAB; 1991.

7 Chizzotti A. A pesquisa em ciências sociais. São Paulo (SP): Cortez; 1995.

8 Caprara A, Veras MSC. Hermenêutica e narrativa: a experiência de mães de crianças com epidermólise bolhosa congênita. Interface: Comunic., Saúde, Educação. 2004 Set-2005 Fev; 9 (16): 131-46.

9 Oliveira RC. O trabalho do antropólogo. São Paulo (SP): Ed. UNESP; 1998.

10 Santana LOPLS. O entardecer no farol: um estudo etnográfico sobre a percepção da saúde entre pessoas idosas [dissertação]. Fortaleza (CE): UECE/Centro de Ciências da Saúde; 2004.

11 Toro P. Teoria da biodanza: mecanismo de acción. Fortaleza (CE): Sistema Rolando Toro; 2001.

12 Moraes MC. Educar na biologia do amor e da solidariedade. Petrópolis (RJ): Vozes; 2003.

13 Olievenstein C. O nascimento da velhice. Bauru (SP): EDUSC; 2001. 